\title{
A Structural Equation Model of Female Empowerment
}

\begin{abstract}
This paper proposes a structural equation model to measure and explain female empowerment in Cambodia. Empowerment is defined as the decision-making ability of a woman regarding her strategic and non-strategic life choices. Grounded in the Capability Approach and in the gender economics literature this conceptualisation accounts for three key elements: resources, values/traditions, and decision-outcomes. These elements interact into a system of structural equations where a latent variable is specified to measure empowerment; decision-outcomes enter as partial metrics of empowerment; and resources, and values/traditions are modelled as exogenous factors. Stochastic dominance analysis is used to compare the empowerment status of women across life choices.
\end{abstract}

Keywords: Female Empowerment, Capability Approach, Structural Equation Modelling, Stochastic Dominance, Cambodia.

JEL classification codes: C3, I21, I31, O54. 


\section{Introduction}

For the last two decades the development agenda has drawn attention to the promotion of gender equality and women's empowerment as a policy goal. The Beijing Platform for Action, the Cairo Program for Action, the Millennium Declaration in 2000 and the United Nations Sustainable Development Summit in September 2015, among other international development platforms, have greatly contributed to this concern. These platforms have acknowledged the intrinsic and instrumental importance of female empowerment and thus, their profound implications for public policy. Consequently, there has been a proliferation of interdisciplinary studies from sociology, anthropology and economics aimed at conceptualising, measuring, and operationalising women's empowerment. These studies have also focused on the impact of policies on female empowerment and of women's empowerment on other desired policy objectives (Narayan, et al. 2009). The empowerment of women has become a primary concern of the sustainable development agenda; not only as a goal per se but also as a necessary condition for multidimensional poverty reduction (UN, 2016).

Conceptually, female empowerment is defined as a complex, context-dependent process rooted in the idea of human agency and choice. As a process empowerment means the progression from a state of disempowerment, a change where women themselves are the significant actors (human agents) having the possibility to choose among real alternatives (Rowlands, 1995; Kabeer, 1999; Sen, 1999; Alkire, 2008; Nussbaum, 2001; Narayan, 2005; Alsop, et al. 2006; Batiwala, 2007).

Drawing on Sen's Capability Approach, Kabeer (1999) furthers this definition and offers a framework that interrelates the main components characterising choice: resources, agency and achievements or decision-outcomes. In her framework, resources are pre-conditions that enhance the ability to choose, agency is a woman's ability to define her goals and act upon them, and achievements or decision-outcomes are one particular manifestation of the ability to choose. Kabeer also highlights the role that preferences, values, and cultural norms play in a woman's ability to choose. Moreover, building on the notion that some choices have greater significance than others in terms of their consequences for a woman's 
life, Kabeer makes a distinction between strategic (or first-order) life choices and nonstrategic (or second-order) life choices. The strategic class refers to those choices that are critical for a woman to live the life she wants to lead, such as marriage and reproduction. The non-strategic class refers to less consequential choices in a woman's life; these are choices that are still important for a woman's quality of life, but do not define it. The definition provided by Kabeer becomes very useful for the operationalisation of female empowerment, as it offers a framework that triangulates and inter-relates the ability to exercise choice while acknowledging its distinction from decision-outcomes.

Many studies had attempted to apply this definition to the empirical field while providing a universalist approach that captures these complexities, on one hand; and allowing for comparability across different population groups, on the other (Malhotra and Schuler, 2005; Alsop, et al. 2006). Although these studies have considerably contributed to the selection of relevant dimensions and to the choice of level of analysis - household, community, or broader arenas - they are silent about the nature of the dimensions, and the interactions among achievements, resources, and values/traditions included in the measurement exercise. Moreover, they found difficulty in measuring the agency aspect characterising empowerment and limit their studies to the measurement of decision-outcomes, which are imperfect and partial metrics of empowerment.

From the economics perspective, the study of female empowerment draws mainly on the literature of intra-household gender dynamics. This literature has studied a variety of models comprising the simplest unitary model (Becker, 1965) to alternative models of household behaviour that better incorporate the complexity of gender relations. These models, known as collective models, account for the individuality of household members and view household behaviour as the outcome of a cooperative or non-cooperative game (Browning, et al 2014). Cooperative collective models further differentiate with regards to the assumptions made about the nature of the decision-making process for intra-household distribution. Two variants of models are prominent in the literature: the Pareto efficient and the bargaining sub-class of models. The Pareto efficient subclass makes no a priori assumptions about the distribution rule governing intra-household allocations, and in addition, 
considers that household decisions are always Pareto optimal (Chiappori, 1988, 1992a,b; Browning and Chiappori, 1998; Bourguignon, et al 1993). The bargaining subclass of models goes one step further and assumes that household decisions result from a bargaining process (Manser and Brown, 1980; McElroy and Horney, 1981). According to these models, intra-household well-being could be affected by improving the exit or threat options of its members. In this context, a woman's bargaining power within her household is defined by the strength of her threat options. Therefore, an improvement of her fall-back position is assumed to enhance her decision-making ability or empowerment. McElroy (1990) emphasises that these exit options are themselves a function of parameters such as a woman's educational level, personal wealth or parental education; hence by these means that policy interventions may improve a woman's fall-back position in a household (c.f. Behrman, 1997).

Despite its wide application in the economics of gender literature, these models fail to accommodate the complexities of gender relations beyond the household. They have little to say about the important role played by social norms, culture, values, and perceptions in the bargaining process (Agarwal, 1997; Quisumbing, 2003).

This paper connects the two branches of the aforementioned literature and thus extends the conceptual definition of empowerment to a more comprehensive and holistic framework grounded on the Capability Approach and on the intra-household gender economics literature. Empowerment is thus defined as the decision-making ability of a woman regarding her strategic and non-strategic life choices where resources, values/traditions, and decisionoutcomes are the key elements characterising a woman's ability to choose. Building on this definition, the paper then proposes a structural equation model to measure and explain female empowerment. In this model the elements characterising 'choice' interact into a system of structural equations, where a latent variable is specified to measure empowerment. This latent or unobserved variable represents the decision-making ability of a woman (feasible decision-making) that is partially and imperfectly measured by her decisionoutcomes, and that is shaped (determined) by 'resources' and values/traditions, modelled as exogenous factors. This holistic approach of constitutive elements provides better in- 
sights into intra-family allocative processes, and successful development assistance programmes. In addition, it offers a metric for empowerment that goes beyond composite indices, such those suggested by the Self-Determination Theory (Deci and Ryan, 2010), and proxies that use education or wealth as metrics of female empowerment. ${ }^{1}$

The model is applied to the study of female empowerment in the context of a country with complex gender relations and strong patriarchal characteristics like Cambodia. Over the past two decades, Cambodia has made remarkable improvements in maternal health, early childhood development, and primary education programs in rural areas, but it still needs to address gender imbalances in basic education, health care delivery HIV/AIDS awareness, employment and income, (USAID, 2006; JICA, 2007; ADB, 2012). These imbalances reflect the prevalence of hierarchies and traditional norms in society that not only favour men but also shape women's status. For instance, while both men and women can inherit property, and the gender division of labour can be complementary and flexible, traditional norms still portray women as household managers with limited decision outside the household. The empirical model specified in this paper uses the 2005 Cambodian Demographic Health Survey, and considers three types of decisions or empowerment domains: 'self and 'familial' strategic life choices, and non-strategic life choices. The results of this model are complemented with an assessment of empowerment across domains using stochastic dominance analysis.

The paper is structured as follows. Section 2 introduces the definition and conceptual framework of empowerment used in the paper. Sections 3 and 4 present the structural equation model and the empirical specification for Cambodia, respectively. Section 5 describes the empirical results. Section 6 concludes.

\section{Conceptual Framework}

Conceptualising female empowerment has been a challenging task for the mainstream literature of gender development. As an important goal in its own right but also as a mean for other goals, empowerment has been conceptualised from a variety of disciplines. Studies from anthropology, economics, demography, and sociology define empowerment as some 
form of choice, control or power (Malhotra and Schuler, 2005; Klein, 2014). However, the relation between power and choice is far from simple and unique. As a socially constructed phenomenon it is shaped by cultural norms, traditions, as well as values and preferences. In this section we present two approaches used to conceptualise female empowerment: Sen's capability approach (Sen, 1999; Kabeer, 1999) and the intra-household gender economics approach (McElroy, 1990; Chiappori, 1992; Quisumbing, 2003; Browning, et al. 2014). Both strands of the literature have been applied in empirical studies of empowerment separately. Our aim in this paper is to reconcile them in order to provide a holistic definition to assess female empowerment.

\section{The Capability Approach}

The Capability Approach (Sen, 1999) is a choice based framework concerned with the expansion of real opportunities (effective choices) that one has in life. In this regard, female empowerment is conceived as the enlargement of effective opportunities that women have in order to live the life they want to lead. However, the role that traditions and cultural norms play in gender relations make of women one of the most disadvantaged groups, one whose ability to choose is more constrained than any other group (Agarwal, 1997; Beneria, et al 2015).

Among the many attempts in the literature seeking this choice characterisation Kabeer's (1999) is found to be the reference (c.f. Malhotra and Schuler, 2005; Klein, 2014). Kabeer's definition, rooted in the capability approach, equates power to choice, with power denoting the ability to make choices. In this perspective, those that do not have this ability are considered to be disempowered. Empowerment is therefore conceptualised as a process, a progression from a state of disempowerment, where women actively involved (human agents) acquire the ability to choose. The idea of process entails a characterisation of potential vis-à-vis actualised choice. This is a process, that differentiates between a woman's decision making-ability (potential choice) and her decision outcomes (actualised choice). However, as noted by Kabeer the relationship between potential and actualised choices is not isolated, but rather, shaped by the action of power through the woman's values and preferences, the institutional norms (traditions) governing her life, and through the 
principles that these norms enforce in the distribution and exchange of resources.

This leads to a representation of empowerment in terms of three inter-related elements: resources, agency, and achievements or decision-outcomes. Resources are pre-conditions that enhance the ability to choose (potential choice), and agency is a woman's ability to define her goals and acts upon them. Resources result from the social relationships that the woman fosters with her family, community, or other institutional domain. Her access to these resources is defined by the norms and rules that regulate distribution and exchange. For instance, for a woman within the institutional domain of the family, with strong patriarchal and patrilineal structures, it is the head of the household (usually a male member) who decides on her access to, and allocation of, resources; whether these are in the form of material resources, say land, or in the form of human resources, say access to education and/or health care.

It is worth noting that these three inter-related elements operate through the woman's values and preferences, and so her choices may reflect her self-denial of choice. In societies with hierarchical gender structures women tend to internalise their social status as persons of lesser value. In this context, their values and preferences may not necessarily reflect their own, but instead these will reflect the values of the institutions in which they live. Thus, in such settings, it is not unexpected that in many situations women will 'choose not to choose' and even go against their own well-being or even support female discrimination. Examples of these situations in South Asian societies are the oppression of mothers-in-law over daughters-in-law, a preference for sons and practices associated with daughter discriminations (Dyson and Moore, 1983; Dreze and Sen, 1997; Das Gupta et al. 2003; Lindsey, 2015).

Finally, a holistic conceptualisation of empowerment would not be complete if one does not differentiate among the type of choices that are meaningful for a woman's life. The agency component of empowerment, previously discussed, points to those decisions that raise the critical consciousness of women regarding those traditions or norms that are taken for granted, but that have a negative impact on their own well-being or that support forms of gender discrimination. This is an additional feature in Kabeer's (1999) definition. She 
differentiates between the consequential significance of choices on a woman's life and categorises them as first and second order choices. The former refers to strategic life choices, which are critical for a woman to live the life she wants to lead. These are choices in critical areas such as marriage, reproduction or friendship that shape the second order group. These are decisions that although important for a woman's quality of life do not constitute her defining parameters.

Many studies had attempted to apply Kabeer's definition empirically but remain silent about the nature of the dimensions to be considered for the assessment, and the interactions among achievements, resources, and values/traditions included in the measurement exercise. Moreover, they found difficulty in measuring the agency aspect characterising empowerment and limit the appraisal of empowerment to decision-outcomes or socioeconomic proxies, which are imperfect and partial metrics of empowerment (c.f. Malhotra and Schuler, 2005; Alsop, et al. 2006).

\section{Intra-household gender economics}

The second conceptual standpoint that has been used for assessing female empowerment comes from the literature of intra-household gender economics. Many decisions that affect the well-being of individuals are made within families or households. Their members, and in particular women, have varying and often conflicting preferences and interests, as well as differential abilities to pursue those interests. Households function as producers, investors in human and physical capital, and as consumers, where individual decisions concerning both labour and resource allocation are made. Evidence from many regions across the world reveals persistent gender inequalities in the distribution of household resources and tasks (Quisumbing, 2003; Kabeer, 2012).

The economics literature has tried to address such complexities within and outside the game theoretic format. The starting point was a critique of Becker's $(1965,1981)$ unitary model of the family. This model also referred to as the common preference model treats the household as a single entity and assumes that all household resources are pooled, and that resources are allocated by an altruistic household head. While attractive for its simplicity and the diversity of issues it can address, the unitary model is being challenged due to its 
restrictive theoretical foundations and empirical disproof for policy design (Behrman, 1997; Laferrere and Wolff, 2006). As alternatives to this model, collective models of household behaviour focus on the individuality of household members and their varying preferences and interests. Two variants are prominent in the existing literature: cooperative and non-cooperative collective models (Chiappori, 1992b; Bourguignon and Chiappori, 1992; Alderman, et al 1995).

The non-cooperative class of models assumes that the actions of members in a household are conditional on the actions of other members. In that sense, the household is described as a site of gender-specific economies linked by reciprocal claims on resources and labour (Lundberg and Pollack, 1993; Browning, et al 2006). In contrast to the non-cooperative approach, the cooperative class of models assumes that individuals have a choice of remaining single or forming a household. Individuals will opt for the latter if the net benefits associated with being married surpass those from being single. The central issue in the cooperative class of models is, therefore, the distribution of the surplus resulting from household formation. The assumptions made about the decision process for distribution lead to two subclasses of collective models: the Pareto efficient and the bargaining sub-class of models.

The Pareto efficient subclass of models makes no a priori assumptions about the rule of distribution governing intra-household allocations and, in addition, considers that household decisions and allocations are always Pareto optimal (Chiappori, 1988, 1992a, b; Browning and Chiappori, 1998; Bourguignon, et al 1993). The bargaining subclass of models goes one step further and assumes a priori that household decisions result from a bargaining process (Manser and Brown, 1980; McElroy and Horney, 1981). According to these models intra-household well-being could be affected by improving the exit or threat options $^{2}$ of its members. Household members cooperate insofar as cooperative arrangements make them better off than non-cooperation (c.f. Behrman, 1997).

In the economics literature female empowerment has been conceptualised and empirically measured along the bargaining approach. In this context, a woman's degree of empowerment is assessed by the strength of her threat option or bargaining power within the house- 
hold. Therefore, an improvement of her fall-back position is assumed to enhance her decision-making ability or empowerment. McElroy (1990) emphasise that these exit options are themselves a function of 'extra-household environmental parameters', such as a woman's educational level, personal wealth or parental education. Agarwal (1997) suggests that female bargaining power in rural areas would depend on eight factors such as a woman's ownership of and control over assets (land), her access to employment and other income earning sources, her educational status, her access to traditional social support systems such as kinship, support from NGO's or the state. It is therefore by means of these parameters or factors that policy interventions may improve a woman's fall-back position in a household and consequently her empowerment (c.f. Behrman, 1997).

It is worth noting that, despite its extensive application in the economics of gender literature, these models fail to accommodate the complexities of gender relations beyond the household, in particular they are unable to account for the important role played by social norms, culture, values, and perceptions in the bargaining process (Agarwal, 1997).

\section{The Model}

The above discussion highlights the limitations of relying on a single approach for the appraisal of female empowerment. As a complex phenomenon the measurement of empowerment shall be grounded on the capability approach and must accommodate the complexities of female relations beyond the household. Therefore, a holistic framework for the appraisal of empowerment needs to reconcile the two branches of the literature previously mentioned.

Empowerment is thus defined as the decision-making ability of a woman regarding her strategic choices in the 'self' and 'familial' domains and non-strategic life choices where resources, values/traditions and decision-outcomes are the key elements characterising a woman's ability to choose. Building on this definition, in this section we propose a struc-

tural equation model, known as a multiple-indicator multiple-causes model (MIMIC), ${ }^{3}$ to measure and explain female empowerment. In this model the elements characterising 'choice' interact into a system of structural equations, where a latent variable is specified to 
measure empowerment in each of the three domains. For a given empowerment domain, this latent or unobserved variable represents the decision-making ability of a woman (feasible decision-making) that is partially and imperfectly measured by her decision-outcomes (observed indicators), and that is shaped (determined) by 'resources' and values/traditions, modelled as exogenous factors. Note that decision outcomes are taken to be manifestations of empowerment and as such are only partial metrics of this latent construct.

Figure 1 depicts this representation where latent variables are denoted by $\eta$, observed decision outcomes by $\boldsymbol{y}$, resources by $\mathbf{x}$ and values/traditions by $\mathbf{w}$. This figure summarises the relationship between i) feasible decision-making (empowerment), decision outcomes and values/traditions, and the one between ii) empowerment and resources. The former is modelled by the connection between $\eta$ and $\boldsymbol{y}$ conditional on $\mathbf{w}$ and is referred to as the measurement model (equation (2) below). The latter is modelled by the connection between $\eta$ and $\mathbf{x}$ and is referred to as the structural model (equation (1) below). ${ }^{4}$

Figure 1: The Model

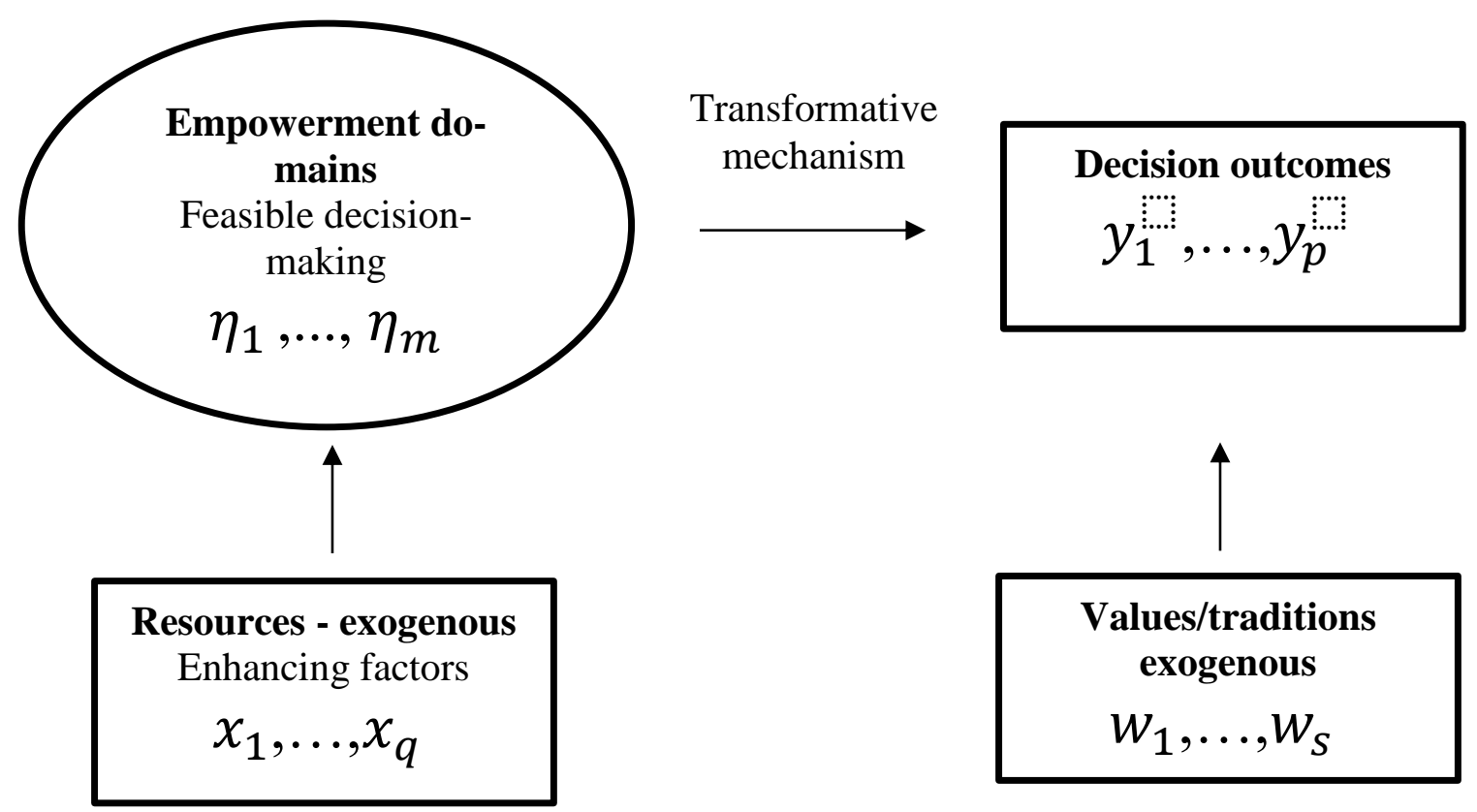

\section{Model specification}

The statistical representation of a structural equation models can be broadly classified into 
two classes of models comprising the full multivariate normality class and the conditional normality one (c.f. Jöreskog, 1973; Jöreskog and Goldberger, 1975; Muthén, 1984; Bollen, 1989; Muthén, 1998-2004). The former assumes that all variables in model, exogenous and endogenous, are multinormally distributed. The latter relaxes this assumption and assumes conditional multivariate normality for the endogenous variables. In this paper we follow the conditional multivariate approach proposed by Muthén (1998-2004) as full multivariate normality is often not realistic.

For a MIMIC specification the 'structural' model is:

$$
\boldsymbol{\eta}_{i}=\alpha+\Gamma \mathbf{x}_{\mathrm{i}}+\zeta_{i}
$$

where $\boldsymbol{\eta}_{i}$ is a $(3 \times 1)$ vector of latent endogenous random variables that represent the degree of empowerment of the $i$-th woman in each of the three domains; $\mathbf{x}_{\mathrm{i}}$ is a $(\mathrm{q} \times 1)$ vector of exogenous variables and includes 'causes' of empowerment and individual characteristics of the woman that have a direct effect on empowerment; $\zeta_{i}$ is a $(3 \times 1)$ vector representing the unknown omitted factors in the explanation of empowerment (random errors); $\boldsymbol{\alpha}$ is a $(3 \times 1)$ intercept parameter vector, and $\boldsymbol{\Gamma}$ is a $(3 \times \mathrm{q})$ slope parameter matrix for the regression of the latent variables of empowerment on resources and individual characteristics of a woman.

As the observed indicators of decision outcomes (y) can be either continuous or qualitative variables, we introduce a response variable $\mathrm{y}^{*}$. This leads to the following 'measurement' model:

$$
\mathbf{y}_{i}^{*}=\boldsymbol{v}+\boldsymbol{\Lambda} \boldsymbol{\eta}_{i}+\mathbf{K} \mathbf{w}_{i}+\boldsymbol{\varepsilon}_{i}
$$

where $\mathbf{y}_{i}^{*}$ is a $(\mathrm{p} \times 1)$ vector of latent response variables; $\boldsymbol{v}$ is a $(\mathrm{p} \times 1)$ parameter vector of measurement intercepts; $\mathbf{w}_{i}$ is a $(\mathrm{m} \times 1)$ vector of exogenous variables and includes: values/traditions, as factors shaping the relationship between empowerment and decision outcomes, and individual characteristics of the woman that have a direct effect on decision outcomes; $\boldsymbol{\varepsilon}_{i}$ is a $(\mathrm{p} \times 1)$ vector or residuals; $\boldsymbol{\Lambda}$ is a $(\mathrm{p} \times 3)$ parameter matrix of measurement slopes or factor loadings; $\mathbf{K}$ is a $(\mathrm{p} \times \mathrm{m})$ parameter matrix of regression slopes. 
With a continuous indicator the latent response model is:

$$
y_{i j}=y_{i j}^{*},
$$

and when it is a categorical variable, we write:

$$
y_{i j}=c, \text { if } \tau_{j, c}<y_{i j}^{*} \leq \tau_{\mathrm{j}, \mathrm{c}+1}
$$

where $\tau_{j, c}$ and $\tau_{\mathrm{j}, \mathrm{c}+1}$ denote the thresholds between categories $c$ and $c+1$.

It is further assumed that the observations are centered without loss of generality, and that the disturbances across individuals are homoscedastic and non-auto correlated, with variance-covariance matrix $\mathrm{V}\left(\boldsymbol{\zeta}_{i}\right)=\boldsymbol{\Psi}$ and $\mathrm{V}\left(\boldsymbol{\varepsilon}_{\boldsymbol{i}}\right)=\boldsymbol{\Theta}$.

On the basis of these stochastic assumptions, the above nonlinear model is estimated using weighted least squares (see Appendix I for details regarding the estimation).

\section{Data}

In this section we present the empirical application of the structural equation model proposed in section three. This MIMIC model is specified to study female empowerment in Cambodia using the 2005 Cambodian Demographic Health Survey (DHS)

This is a nationally representative survey that collects data on reproductive health issues for women aged 15 to 49 years. In addition for ever-married women the survey gathers information concerning a woman's spouse selection, spouse's education and age, decisionmaking outcomes, education, attitudes toward gender roles, children education and health care, and domestic violence, as well as, her labour force participation, parental education, control of earnings and expenditures, awareness of HIV-AIDS, and media exposure.

As our study is concerned with the appraisal of female empowerment regarding self and familial life choices as well as non-strategic ones, the sample we consider includes all married women aged 15 to 49 years having at least one living child. This leads to a sample size of 2385 women. 


\section{Selection of decision-outcomes, resources, and values}

An important aspect in the empirical application concerns the selection of the indicators (decision outcomes) in each empowerment domain, the 'resources' that pre-condition the ability to choose, and the values and traditions that shape the choice process. To select these variables we draw on the studies performed by Kabeer(2001), Kishor (2000), Jejeebhoy and Sathar (2001), Malhotra and Schuler (2005), Alsop, et al.(2006), and Narayan, et al. (2009). Most of these studies include surveys of the literature on indicators, domains of empowerment and factors influencing empowerment, thus providing us with a sound conceptual support for this selection.

With regards to decision outcomes as metrics for the self- strategic empowerment domain Kabeer (2001), Kishor (2000), and Jejeebhoy and Sathar (2001) suggest indicators that reflect decisions on marriage, access to health care, and freedom of movement. For the familial strategic life choices domain, these studies suggest indicators reflecting decisions about having another child, and about children's education and access to health care. For the non-strategic empowerment dimension Kabeer (2001) recommends focusing on second-order economic choices. Malhotra and Schuler (2005), Alsop, et al. (2006) and Narayan, et al. (2009) suggest, then, using as metrics of economic choices indicators denoting decisions about participating in large household purchases (economic decision-making), daily need purchases (domestic decision making), and decisions about a woman's labour force participation (Table 1).

In the case of Cambodia, the 2005 DHS asked a woman whether the decision has been the husband's or someone else's, has been made with the husband or someone else, or was entirely hers. These responses are represented by a three-category ordered variable where the highest category denoting greater decision outcome refers to a decision made entirely by the woman, whereas the lowest is given by a decision that concerns the woman but was made by her husband or someone else; joint decisions are placed in the middle of the categorical scale. Table 1 reports the frequencies of responses for each decision outcome. In the case of self- strategic decision outcomes, we observe that the indicator exhibiting the greatest decision outcome is that of access to health care, with $60.8 \%$ of women having a final say on these decisions. In contrast, decisions about spouse selection and freedom of 
movement are mainly carried out with the husband or someone else (around 63\% of respondents). It is interesting to note that $15.9 \%$ of women do not intervene in decisions concerning the selection of their spouse, thus reflecting, in some extent, traditions of arranged marriage. Regarding familial strategic decision outcomes we observe that all three decisions are mostly taken jointly; however $20.8 \%$ of children's health care decisions are taken exclusively by the mother. Finally, in the case of second order economic choices we observe an interesting pattern with a considerable large percentage of women (80\%) having a final say on small household purchases, but a much lower percentage deciding alone about big household purchases (16.4\%). These latter decisions are mostly taken with the husband or someone else $(65.6 \%)$. This is also the case of decisions about labour force participation where $56.7 \%$ of women decide jointly about their labour active participation and only $19 \%$ decide alone. These frequencies suggest that women seem to have greater decision outcomes concerning their self-strategic domain compared to the familial one or to the economic choice domain.

Table 1: Distribution of decision-outcome indicators (in \%)

Dimension/indicator

Self strategic choices

Spouse selection

Deciding on obtaining health care

Deciding about visiting family and friends

(freedom of movement)

\section{Familial strategic choices}

Deciding on having another child

Participating in children's acces to health care

Participating in children's education

Second-order economic choices

Participating in economic decision-making

Participating in domestic decision-making

Deciding whether to work or not

\section{Husband's \\ or someone else's}

15.9

3.4

6.4
With husband

or someone else

63.5

35.8

63.8
Respondent's

20.6

60.8

29.7

$\begin{array}{lll}7.3 & 79.2 & 13.5 \\ 3.1 & 76.1 & 20.8 \\ 7.3 & 81.1 & 11.5\end{array}$

With regards to the selection of variables denoting resources, these include factors that cause or determine a woman's ability to choose, and a woman's individual factors having a 
direct impact on empowerment per se. Kabeer(2001), Kishor (2000), Jejeebhoy and Sathar (2001), and Malhotra and Schuler (2005) identify education (of the woman and her parents') and wealth as the most important enhancing factors of female empowerment. Kabeer (2001), Alsop, et al. (2006), and Narayan, et al. (2009) suggest age at marriage, and age and educational difference between a woman and her spouse, as key determinants of female empowerment. For our purposes, we categorise the latter as individual factors of the structural equation. Thus, in the case of Cambodia we include three indicators of education - the respondent's level of education, and her mother's and father's; an indicator of the respondent's possession of assets and wealth, and three individual 'direct' factors - the respondent's age at marriage, and her age and educational difference with the spouse. We would expect a positive effect of the educational variables and of material welfare on empowerment, and a negative effect of age and educational difference between spouses (Table 2).

Table 2 presents the frequency of responses of these causes of empowerment. A comparison of the respondents' maternal and paternal level of education shows a contrasting pattern with $46 \%$ of women having mothers with no education, compared to only $14 \%$ in the case of their fathers. Moreover, $52 \%$ of women have a father with an educational level between primary and secondary. Moving to the woman's education we observe that almost $60 \%$ of women have primary education as their highest education level, but $25.8 \%$ of them still exhibit no education and only $16 \%$ of them have attained secondary or higher educational levels. With regards to direct individual factors, we observe that $67 \%$ of women in our sample were between 16 and 21 years old at the time of their marriage, and only $6 \%$ of them got married after 26 years old showing that females in Cambodia tend to get married very young. The age and educational differences between spouses shows a high proportion of women marrying men older than them with $42.4 \%$ of them being married to men that are 1 to 4 years older. These women are often more or equally educated than their husbands $(65 \%)$. 
Table 2: Causes of empowerment

(Frequencies)

\begin{tabular}{llr}
\multicolumn{1}{c}{ Variable } & \multicolumn{1}{c}{ Categories } & \% \\
\hline $\begin{array}{llr}\text { Mother's level } \\
\text { of education }\end{array}$ & None & 46.2 \\
& Primary & 21.5 \\
In between & 30.1 \\
Father's level & Secondary or higher & 2.2 \\
of education & None & 14.3 \\
& Primary & 24.6 \\
Level of education & In between & 51.9 \\
(respondent's) & Secondary or higher & 9.2 \\
& No education & 25.8 \\
Age at marriage & Primary & 58.3 \\
(respondent's) & Secondary or higher & 15.9 \\
& <16 & 10.2 \\
& $16-18$ & 36.2 \\
& $19-21$ & 31.2 \\
Age difference & 22-25 & 16.8 \\
between spouses & 26 or older & 5.7 \\
& Wife older or no difference & 27.0 \\
Educational difference & Husband 1 or 4 years older & 42.4 \\
between spouses & Husband 5 or more years older & 30.6 \\
\hline & Same education & 65.4 \\
\hline
\end{tabular}

Lastly, concerning the selection of variables denoting values and traditions, Kabeer (2001), Alsop, et al. (2006), and Narayan, et al. (2009) suggest questions about gender roles, justified domestic violence, wife's participation in discussions about money matters, awareness of HIV-AIDS, exposure to mass media, living with in-laws, support from birth family and labour force participation (Table 3). Among these factors we observe that $97.5 \%$ of women in the sample is aware about AIDS, 94\% is Buddhist, while $8.8 \%$ live with in-laws. In addition, we observe that $80.1 \%$ of women count on support from their birth family, $62.6 \%$ participate in the labour force, and $68.8 \%$ are exposed to mass media. Interestingly, a third of the sample agrees with 'justified' domestic violence, and also with female participation in discussions of money matters. 
Table 3: Values and traditions: percentage of women who agree

\begin{tabular}{|c|c|}
\hline Variable & $\begin{array}{c}\text { Yes } \\
(\%)\end{array}$ \\
\hline Disagree with socially recognized gender roles & 24.3 \\
\hline Agree with 'justified' domestic violence & 33.9 \\
\hline $\begin{array}{l}\text { Agree that wifes should participate } \\
\text { in discussions about money matters }\end{array}$ & 34.5 \\
\hline Are aware of HIV-AIDS & 97.5 \\
\hline Are exposed to mass media & 68.8 \\
\hline Live with in-laws & 8.8 \\
\hline Have support from birth family & 80.1 \\
\hline Participate in the labor force (working status) & 62.6 \\
\hline Are buddist & 94.3 \\
\hline
\end{tabular}

\section{Results}

In this section we report the results of the econometric model for Cambodia. Figure 2 presents the path diagramme of this model which is a graphical representation of the econometric specification to measure empowerment in Cambodia using the DHS of 2005. In this diagramme circles denote latent variables and rectangles denote observed variables. The latent variables represent the decision-making ability of a woman (feasible decisionmaking) that is partially and imperfectly measured by her decision outcomes, and that is shaped (determined) by a woman's 'resources'- left-hand side variables of the figure, and values/traditions - right-hand side of the figure. Note that each empowerment domain is measured by three categorical indicators.

The results of this model are reported in Tables 4 to $7 .^{5}$ As each variable has a different unit of measurement we report the estimated values of standardised parameters so that we can compare their effects across equations and variables. The standardisation in each equation is performed by multiplying the estimated parameter by the ratio of the standard deviation of the explanatory variable to the standard deviation of the explained variable. Overall, the model shows a relative good fit as shown by the values of the CFI and TLI incremental 
fit indices both above the threshold of good fit of 0.7 ( 0.8 and 0.87 , respectively) and the root mean square error of approximation below the 0.05 cut-off. $^{6}$

\section{Figure 2: Cambodia empowerment model Path-diagram}

\section{Decision-making ability}

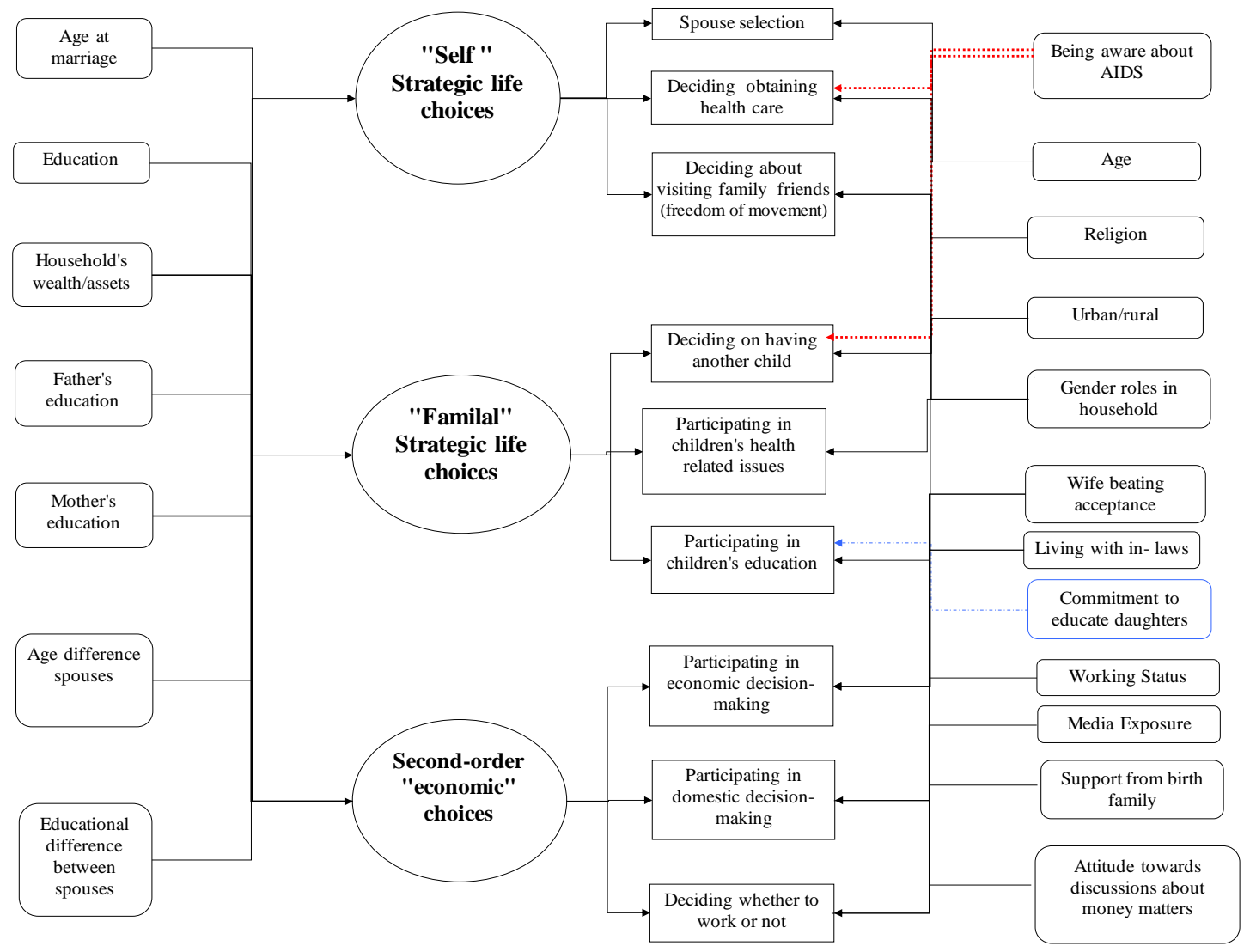

The results of the measurement model of self-strategic life choices show factor loadings ${ }^{7}$ ( $\Lambda$ parameters) of 0.051 for spouse selection, 0.44 for freedom of movement, and 0.597 for decisions about obtaining health care. This means that the impact of a unit change in feasible decision-making of strategic choices is not uniform across the three decision-outcomes, with the greatest impact being that on health care (Table 4). Similarly, in the case of familial strategic life choices a unit improvement of empowerment in this dimension would lead to an improvement of 0.716 standard deviation units in decisions concerning children's health, 0.55 in decisions about children's education, and 0.33 in decisions about having a new child Clearly the impact is much greater than the one exhibited in the self-domain (Table 5). Factor loadings of second-order economic choices are more uniform thus domes- 
tic decision making will improve in 0.56 standard deviations if empowerment improves in one unit. This impact is lower for economic decision-making (0.5) and for decisions about labour force participation (0.31) (Table 6).

\section{Table 4: Measurement Model Results - Self Strategic life choices}

\begin{tabular}{|c|c|c|c|c|c|c|c|}
\hline \multirow{2}{*}{ 更 } & \multirow{2}{*}{ Variable } & \multicolumn{2}{|c|}{ Spouse selection } & \multicolumn{2}{|c|}{ Own health care } & \multicolumn{2}{|c|}{$\begin{array}{c}\text { Visiting family } \\
\text { and friends }\end{array}$} \\
\hline & & $\begin{array}{r}\mathrm{y}_{1} * \\
\text { Standard. } \\
\text { Coeff. } \\
\end{array}$ & Signif. & $\begin{array}{l}\mathrm{y}_{2}{ }^{*} \\
\text { Standard. } \\
\text { Coeff. }\end{array}$ & Signif. & $\begin{array}{c}\mathrm{y}_{3}{ }^{*} \\
\text { Standard. } \\
\text { Coeff. } \\
\end{array}$ & Signif. \\
\hline \multirow{10}{*}{$\eta_{1}$} & "Self" Strategic life choices & 0.051 & $* * *$ & 0.597 & $* * *$ & 0.440 & \\
\hline & Age & -0.082 & $* * *$ & & - & 0.137 & $* * *$ \\
\hline & Being buddist & -0.093 & $* * *$ & 0.129 & $* * *$ & 0.04 & $* * *$ \\
\hline & Being muslim & -0.122 & $* * *$ & 0.069 & $* * *$ & & - \\
\hline & Being aware of HIV-AIDS & & - & 0.025 & $* * *$ & & - \\
\hline & Gender roles in household & & - & 0.046 & $* *$ & 0.079 & $* * *$ \\
\hline & Living with in-laws & & - & & - & 0.042 & $* *$ \\
\hline & Wife beating acceptance & & - & & - & -0.067 & $* * *$ \\
\hline & Support from birth family & & - & & - & 0.071 & $* * *$ \\
\hline & Working status & & - & & - & 0.047 & $* * *$ \\
\hline
\end{tabular}

\section{Table 5: Measurement Model Results - Familial Strategic life choices}

\begin{tabular}{|c|c|c|c|c|c|c|c|}
\hline \multirow{3}{*}{ 更 } & \multirow{3}{*}{ Variable } & \multicolumn{2}{|c|}{$\begin{array}{l}\text { Having another } \\
\text { child } \\
\end{array}$} & \multicolumn{2}{|c|}{$\begin{array}{c}\text { Children's } \\
\text { health }\end{array}$} & \multicolumn{2}{|c|}{$\begin{array}{l}\text { Children's } \\
\text { education }\end{array}$} \\
\hline & & $\mathrm{y}_{4} *$ & & $\mathrm{y}_{5} *$ & & $\mathrm{y}_{6} *$ & \\
\hline & & $\begin{array}{c}\text { Standard. } \\
\text { Coeff. }\end{array}$ & Signif. & $\begin{array}{c}\text { Standard. } \\
\text { Coeff. }\end{array}$ & Signif. & $\begin{array}{c}\text { Standard. } \\
\text { Coeff. }\end{array}$ & Signif. \\
\hline \multirow[t]{10}{*}{$\eta_{2}$} & "Familial" Strat.choices & 0.334 & $* *$ & 0.716 & & 0.550 & $* * *$ \\
\hline & Age & -0.126 & $* * *$ & 0.032 & - & 0.446 & $* * *$ \\
\hline & Crossed effect: buddist and rural & -0.03 & - & & - & & - \\
\hline & Being buddist & & - & 0.102 & $* * *$ & 0.068 & $* * *$ \\
\hline & Being muslim & & - & 0.071 & $* * *$ & 0.062 & $* * *$ \\
\hline & Being aware of HIV-AIDS & 0.028 & $*$ & & - & & - \\
\hline & Gender roles in household & & - & & - & 0.07 & $* * *$ \\
\hline & Living with in-laws & & - & -0.053 & $* * *$ & & - \\
\hline & Living in rural areas & & - & -0.072 & $* * *$ & & - \\
\hline & Working status & & - & & - & 0.044 & $* *$ \\
\hline
\end{tabular}

The role played by values/traditions also varies by indicator of decision outcome (Tables 4 to 6). We see that living with in-laws, a tradition in Cambodia, has a positive impact on freedom of movement (0.042) and a negative impact on children's health-related issues (0.053). This result suggests that the presence of in-laws, mainly mother in-law, would be 
prejudicial for a young mother's empowerment. Attitudes towards gender roles in household have a positive influence on all indicators of non-strategic choices, also on decisions about children's education, and on decisions about the woman's health care, with the strongest effect being on economic decision-making. This highlights the importance to raise the critical consciousness of women regarding those traditions and norms which are taken for granted, but have a negative impact on their own well-being or support forms of gender discrimination.

Another appealing result is the awareness of HIV-AIDS. This variable influences positively decisions about the woman's health. Deciding about access to health care will improve in 0.02 units with each unit of extra HIV-AIDS awareness. Similarly, decisions about having a new child also improve in 0.02 units. Support from birth family turns out to be significant only for explaining freedom of movement decisions, while attitudes towards female participation in money matters influence positively big purchase decisions. These two variables have an impact of 0.07 on the respective indicator.

In addition, having a source of income (working status) has a positive impact on decisions regarding: large purchases, children's education, and freedom of movement. This indicates that women who 'work' will have greater freedom in deciding about important economic matters, educating their children, or moving freely.

Wife-beating acceptance and domestic violence have a negative effect on freedom of movement thus indicating that women who suffer from domestic violence will see their social and familiar contacts limited. Finally, we see that being Buddhist has a negative influence on spouse selection, but a positive one on large (economic) and small (domestic) household purchases, and on children's health and education decisions. 


\section{Table 6: Measurement Model Results - Second order economic choices}

\begin{tabular}{|c|c|c|c|c|c|c|c|}
\hline \multirow{3}{*}{ 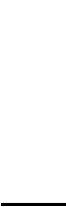 } & \multirow{3}{*}{ Variable } & \multicolumn{2}{|c|}{ decision-making } & \multicolumn{2}{|c|}{ decision-making } & \multicolumn{2}{|c|}{ decision } \\
\hline & & \multicolumn{2}{|c|}{$\mathrm{y}_{7}^{*}$} & \multicolumn{2}{|c|}{$\mathrm{y}_{8}{ }^{*}$} & \multicolumn{2}{|c|}{$\mathrm{y}_{9}^{*}$} \\
\hline & & $\begin{array}{c}\text { Standard. } \\
\text { Coeff. }\end{array}$ & Signif. & $\begin{array}{c}\text { Standard. } \\
\text { Coeff. }\end{array}$ & Signif. & $\begin{array}{c}\text { Standard. } \\
\text { Coeff. }\end{array}$ & Signif. \\
\hline \multirow[t]{9}{*}{$\eta_{3}$} & Second-order "economic" choices & 0.509 & $* * *$ & 0.562 & & 0.317 & $* * *$ \\
\hline & Age & 0.207 & $* * *$ & 0.225 & $* * *$ & 0.108 & $* * *$ \\
\hline & Being buddist & 0.126 & $* * *$ & 0.123 & $* * *$ & & - \\
\hline & Being muslim & 0.117 & $* * *$ & 0.074 & $* * *$ & & - \\
\hline & Crossed effect: buddist and rural & & - & & - & -0.057 & $* * *$ \\
\hline & Gender roles in household & 0.111 & $* * *$ & 0.078 & $* * *$ & 0.087 & $* * *$ \\
\hline & Working status & 0.056 & $* * *$ & & - & 0.27 & $* * *$ \\
\hline & Attitude towards discussions & & & & & & \\
\hline & about money matters & 0.071 & $* * *$ & & - & & - \\
\hline
\end{tabular}

Moving onto the causal factors of empowerment, the results of the structural model reported in Table 7 indicate that parental education, especially the father's, has a strong enhancing effect on each of the three dimensions of empowerment. The causal effect of the father's education ranges from 0.094 on non-strategic decisions, to 0.087 on self-decisions, and to 0.069 on familial decisions. This shows that improvements in the father's education will lead to greater decision-making ability of women not only on second-order choices but also on critical choices such as the self-strategic ones and, in a lesser extent, on the familial ones. Mother's education has also a positive causal effect but only significant on self and familial empowerment choices. Thus self-strategic empowerment will be enhanced in 0.09 units when the mother's education improves in one standard deviation unit; and in 0.069 units in the case of familial strategic choices. This indicates that improvements in a woman's maternal education will have potential benefits on her empowerment in strategic choices, but no so in economic ones, which is improved with the father's education.

Household's wealth is statistically significant in explaining self and familial decision making ability. The effect is greater than parental education, thus showing the importance of material household resources on the ability to take decisions. Household assets are among the significant determinants of non-strategic choices although their effect is half the effect of the wealth variable $(0.06)$. 
Interestingly, the woman's education determines each of the three empowerment domains with the stronger effect being on self-strategic choices $(0.10)$, followed by non-strategic choices $(0.08)$, and by familial choices $(0.06)$. This confirms the role that female education has as determinant of their degree of empowerment. Lastly, age at marriage has a causal impact only on non-strategic choices (0.067).

Table 7: Structural Model Results - Causes of empowerment

\begin{tabular}{|c|c|c|c|c|c|c|}
\hline \multirow{3}{*}{ Variable } & \multicolumn{2}{|c|}{$\begin{array}{c}\text { "Se If" } \\
\text { strategic choices }\end{array}$} & \multicolumn{2}{|c|}{$\begin{array}{c}\text { "Familial" } \\
\text { strategic choices }\end{array}$} & \multicolumn{2}{|c|}{$\begin{array}{c}\text { Second-order } \\
\text { "economic" choices } \\
\end{array}$} \\
\hline & $\overline{\eta_{1}}$ & & $\eta_{2}$ & & $\eta_{3}$ & \\
\hline & $\begin{array}{c}\text { Standardized } \\
\text { Coeff. } \\
\end{array}$ & Signif. & $\begin{array}{c}\text { Standardized } \\
\text { Coeff. } \\
\end{array}$ & Signif. & $\begin{array}{c}\text { Standardized } \\
\text { Coeff. } \\
\end{array}$ & Signif. \\
\hline Age at marriage & & - & & - & 0.067 & $* *$ \\
\hline Woman's education (years) & 0.101 & $* * *$ & 0.061 & $* * *$ & 0.081 & $* * *$ \\
\hline Household's wealth & 0.126 & $* * *$ & 0.112 & $* * *$ & & \\
\hline Household's assets & & & & & 0.064 & $* * *$ \\
\hline Father's education (years) & 0.087 & $* * *$ & 0.069 & $* * *$ & 0.094 & $* * *$ \\
\hline Mother's education (years) & 0.090 & $* * *$ & 0.063 & $* * *$ & & - \\
\hline
\end{tabular}

We conclude the analysis by assessing the relative importance of the three empowerment dimensions across the sample. For this purpose, we apply first-order stochastic dominance analysis (Davidson and Duclos, 2000; Duclos and Araar, 2006). Higher orders of dominance are not feasible when dealing with latent variables due to the lack of cardinality of the scores. ${ }^{8}$ First-order dominance uses only the ordinal information of the distributions in question, however second or higher orders require cardinal information. This is the reason why we restrain our comparisons to the first-order case. To proceed we first normalise the fitted distributions of factor scores so that their measurements scales become comparable. On the basis of these normalised distributions we compare the empowerment status across dimensions. This leads to three pairs of stochastic dominance comparisons, among which we find first-order dominance only between the strategic and familial life choices domains. In Figure 3 we report dominance curves for this pair of variables. On the horizontal axis we plot the estimated values of the empowerment variables (factor scores) and on the vertical axis we plot the cumulative distribution functions of self and familial empowerment. As 
shown in Figure 3, the empowerment of women is greater in the self-strategic domain(curve is always below) compared to the familial one.

Figure 3: Stochastic dominance curves

\section{Self and familial empowerment cumulative distribution functions}

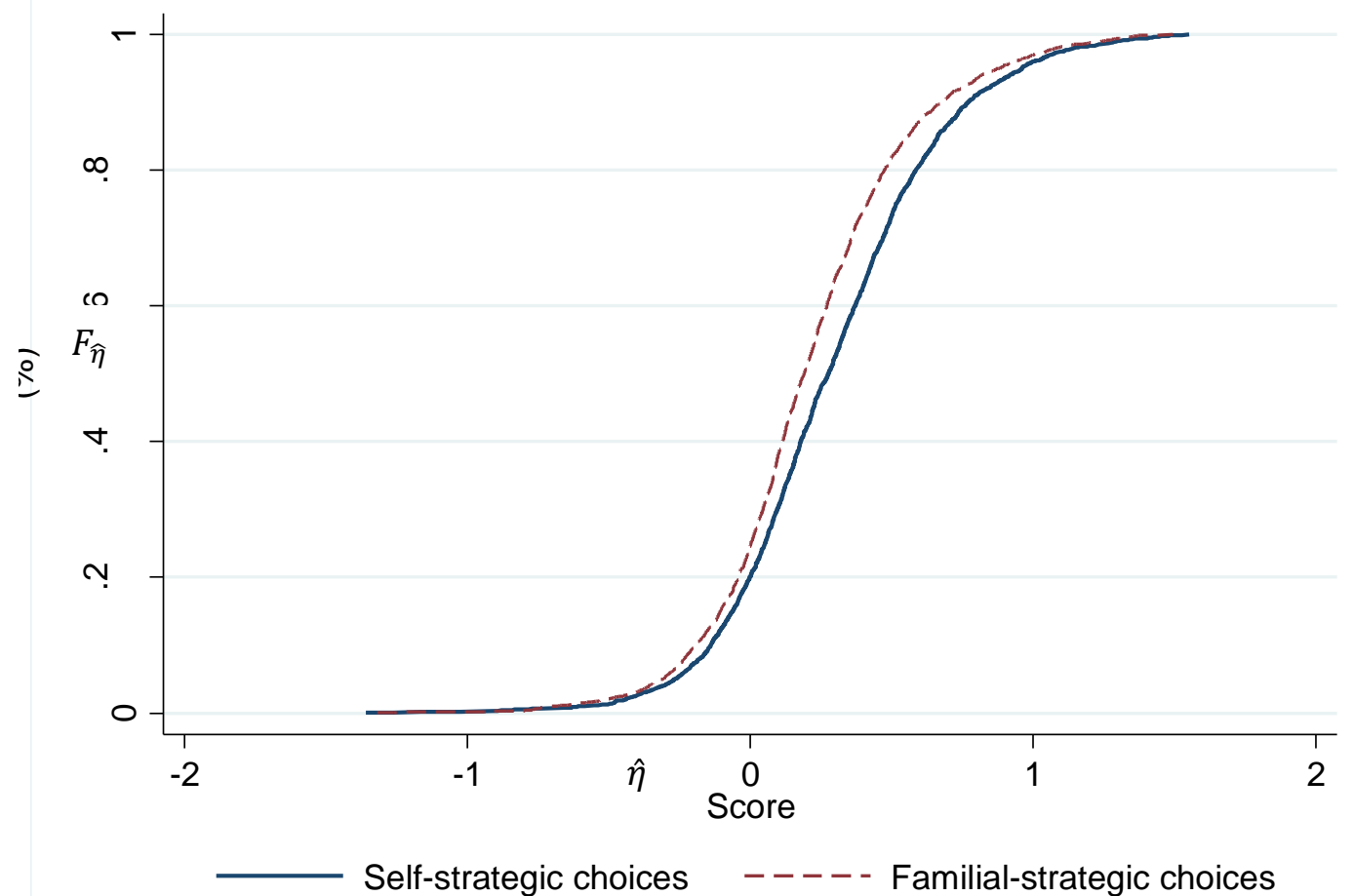

\section{Conclusions}

In this paper we reconcile the economics literature of intra-household gender dynamics with Sen's Capability Approach. By doing so, the paper aims to contribute to the literature of female empowerment on metrics and definitions. Building on these two strands of the literature, we defined empowerment as the decision-making ability of a woman regarding her strategic and non-strategic life choices. We disentangled three key elements characterising a woman's ability to choose: her resources, values/traditions, and decision-outcomes. Using this definition, the paper then proposed a multiple-indicators multiple-causes model 
to measure and explain female empowerment. In this model the elements characterising 'choice' interact into a system of structural equations, where a latent variable is specified to measure empowerment. This latent or unobserved variable represents a woman's decisionmaking ability (feasible decision-making) that is partially and imperfectly measured by her decision-outcomes, and that is shaped (determined) by a woman's 'resources' and values/traditions, modelled as exogenous factors. We applied this model to study female empowerment in Cambodia using the 2005 Demographic Health Survey, and considered three types of decisions or empowerment domains: 'self' and 'familial' strategic life choices, and non-strategic life choices.

The results of the measurement models showed that traditions like living with in-laws could be prejudicial for a young mother's empowerment when it comes to decide about children's health issues; that attitudes towards gender roles have a positive influence on several decision outcomes, and that awareness of HIV-AIDS has a positive effect on health decision issues. These results highlight the importance of raising the critical consciousness of women regarding those traditions, which are taken for granted, but have a negative impact on their own well-being or support forms of gender discrimination. Lastly, the negative effect of wife-beating acceptance on female's freedom of movement clearly indicates that women suffering from domestic violence will be limited in their daily social life.

The results of the structural model confirm the importance of education of both the woman's and her parents', especially her father's, where we find the greatest impact as a determinant of empowerment. Likewise, we find empirical evidence of the causal influence of household's wealth in explaining self and familial decision making ability, and of household's assets as the determinants of non-strategic choices.

The cross-comparison of the empowerment distributions through dominance analysis showed that women in Cambodia are unambiguously better off in the domain of selfstrategic choices than in the altruistic component of familial choices. This result provides better insights for intra-family allocative processes, and successful development assistance programmes. 


\section{Appendix I - Estimation}

The MIMIC model specified in Section III is estimated by minimising the distance between the sample moments of the observed variables, and the corresponding theoretical moments expressed as a function of the unknown parameters. This leads to the following fitting function:

$$
F_{W L S}(\boldsymbol{\pi})=\frac{1}{2}(\mathbf{s}-\boldsymbol{\sigma})^{\boldsymbol{T}} \mathbf{W}^{-\mathbf{1}}(\mathbf{s}-\boldsymbol{\sigma}),
$$

where $\mathbf{s}$ is the sample mean vector and sample covariance matrix ${ }^{9}, \boldsymbol{\sigma}$ is the mean and covariance matrix implied by the model (function of the model parameters), $\boldsymbol{\pi}$ is the vector of model parameters (it includes regression slopes, intercepts, factor loadings and disturbances), and $\mathbf{W}^{-\mathbf{1}}$ is the inverse of a weight matrix.

Following Muthén(1998-2004) there are three steps to the model estimation using weighted least squares by (5). First, intercepts, conditional first moments $E\left(\mathbf{y}^{*} \mid \mathbf{x}, \mathbf{w}\right)$ and conditional second order moments $V\left(\mathbf{y}^{*} \mid \mathbf{x}, \mathbf{w}\right)$ are estimated as $\mathbf{s}$. Using these estimates in a second step, a weighting matrix $\mathbf{W}$ is formed as an estimate of the asymptotic covariance matrix s. Lastly, the parameters of the model are estimated by minimising the weighted least squares fitting function given by (5). The variance of the estimates is corrected using the well-known 'sandwich' formula under non-normality or quasi- maximum likelihood (White, 1982; Gouriéroux, et al., 1984)

Once the parameter estimates are obtained, the final step consists in the estimation of the vector of latent variables for each person. These are called factor scores and could be estimated by various methods. Following the empirical Bayesian approach, which is a standard procedure suggested in the related literature (Skrondal and Rabe-Hesketh, 2004), the latent factors are estimated by their posterior means (modes) given the sample and replacing the parameter values by their estimates.

\footnotetext{
${ }^{1}$ For a discussion of the limitations of proxy indicators as metrics of empowerment see Klein and Ballon (2016).

${ }^{2}$ The threat options reflect the well-being status of a household member if cooperation fails.

${ }^{3}$ SEM's are regression equations that express relationships between observed and unobserved or latent variables. The general structural equation model consists of two types of models: a measurement model that specifies the relationship between observed and latent variables, and a latent or structural model that shows the
} 
influence of latent variables on each other. MIMIC models are a special case of SEMs where the measurement model contains observed variables that are multiple indicators of the latent variable, and the structural model contains multiple causes (or explanatory variables) of the latent variable. These models have been widely applied in social psychology, sociology (Bollen, 1989; Bollen and Curran, 2006) and also in development economics (Kuklys, 2005; Krishnakumar and Ballon, 2008). In the area of gender studies we find very few examples among which we may cite Pitt et al. (2006) who used a MIMIC model to analyse the impact of microcredit program participation on empowerment.

${ }^{4}$ As is standard in the SEM literature, latent variables are denoted by a circle while observed indicators and observed explanatory variables are denoted by a rectangle. The direction of the arrow indicates the sense of causality. Bold symbols denote vectors.

${ }^{5}$ Note that the model that was estimated is the one described in Figure 2, and for clarity purposes in tables 47 we only report variables that were statistically significant (at 5, or $10 \%$ levels).

${ }^{6}$ The root mean square error (RMSEA) is an absolute fit statistic that determines how well a model fits the sample data (see Browne and Cudeck, 1993; Steiger and Lind, 1980). It is regarded as one of the most informative fit indices as it favours parsimony. Browne and Cudeck (1993) recommend a value of less than 0.5 for reasonably well-fitting models. Other conventional fit indices include the comparative fit index (CFI) and the non-normed fit index also known as the Tucker-Lewis index (TLI). Unlike the RMSEA fit measure the CFI and the TLI are relative fit statistics and their calculation relies on a comparison with a baseline or null model (Bentler, 1990). The TLI assesses a model by comparing the chi-square value of the model with that of a null, and the CFI performs a comparison with the null model using the sample correlation matrix. In both cases, the null model assumes independence and specifies that all variables are uncorrelated. Values of these statistics range from 0 to 1 with values closer to 1 indicating good fit.

${ }^{7}$ Factor loadings show the expected change in the decision outcome indicator following a one unit change in the latent variable or empowerment domain in our case.

${ }^{8}$ It is important to mention that the scores are purely ordinal (but continuous) in nature, hence their actual value or metric has no intrinsic meaning, but only in comparison with another value.

${ }^{9}$ When the observed indicators $(y)$ are categorical, $\mathbf{s}$ is computed by a set of $p$ probit regressions of each $y$ on all $\mathbf{x}$ and $\mathbf{w}$ variables, followed by a set of $p(p-1) / 2$ bivariate probit regressions of each pair of $y$ variables on all $\mathbf{x}$ and $\mathbf{w}$ variables. 


\section{References}

Agarwal, B. (1997). "Bargaining"and gender relations: Within and beyond the household. Feminist economics, 3(1), 1-51.

Alderman, H., Chiappori, P. A., Haddad, L., Hoddinott, J., \& Kanbur, R. (1995). Unitary versus collective models of the household: is it time to shift the burden of proof?. The World Bank Research Observer, 10(1), 1-19.

Alkire, S. (2008). Concepts and measures of agency (No. OPHI WP 010). Queen Elizabeth House, University of Oxford.

Alsop, R., Bertelsen, M. F., \& Holland, J. (2006). Empowerment in practice: From analysis to implementation. World Bank Publications.

Asian Development Bank (ADB). 2012. Cambodia: Country Gender Analysis Manila.

Batliwala, S. (2007). Taking the power out of empowerment-an experiential account. Development in practice, 17(4-5), 557-565.

Becker, G. S. (1965). A Theory of the Allocation of Time. The economic journal, 493-517.

Becker, G. S. (1981). Altruism in the Family and Selfishness in the Market Place. Economica, 48(189), 1-15.

Benería, L., Berik, G., \& Floro, M. (2015). Gender, development and globalization: economics as if all people mattered. Routledge.

Behrman, J. R. (1997). Intrahousehold distribution and the family. Handbook of population and family economics, $1,125-187$.

Bentler, P. M. (1990). Comparative fit indexes in structural models. Psychological bulletin, 107(2), 238.

Bollen, K. A. (1989). Structural equations with latent variables. NY: Wiley.

Bollen, K. A., \& Curran, P. J. (2006). Latent curve models: A structural equation perspective. John Wiley \& Sons.

Bourguignon, F., \& Chiappori, P. A. (1992). Collective models of household behavior: An introduction. European Economic Review, 36(2), 355-364. 
Bourguignon, F., Browning, M., Chiappori, P. A., \& Lechene, V. (1993). Intra household allocation of consumption: A model and some evidence from French data. Annales d'Economie et de Statistique, 137-156.

Browne, M. W., \& Cudeck, R. (1993). Alternative ways of assessing model fit. Sage focus editions, 154, 136-136.

Browning, M., \& Chiappori, P. A. (1998). Efficient intra-household allocations: A general characterization and empirical tests. Econometrica, 1241-1278.

Browning, M., Chiappori, P.A. \& Weiss, Y. (2014) Economics of the Family, Cambridge University Press

Browning, M., Chiappori, P. A., \& Lechene, V. (2006). Collective and unitary models: A clarification. Review of Economics of the Household, 4(1), 5-14.

Chiappori, P. A. (1988). Rational household labor supply. Econometrica: Journal of the Econometric Society, 63-90.

Chiappori, P. A. (1992a). Collective Labor Supply and Welfare. Journal of Political Economy, 437-67.

Chiappori, P. A. (1992b). "Collective" Models of Household Behavior: The Sharing Rule Approach. DELTA.

Das Gupta, M., Zhenghua, J., Bohua, L., Zhenming, X., Chung, W., \& Hwa-Ok, B. (2003). Why is son preference so persistent in East and South Asia? A cross-country study of China, India and the Republic of Korea. The Journal of Development Studies, 40(2), 153-187. Davidson, R., \& Duclos, J. Y. (2000). Statistical inference for stochastic dominance and for the measurement of poverty and inequality. Econometrica, 68(6), 1435-1464.

Deci, E. L., \& Ryan, R. M. (2010). Self-determination. John Wiley \& Sons, Inc..

Dreze, J., \& Sen, A. (1997). Indian development: Selected regional perspectives. Oxford University Press.

Duclos, J. Y., \& Araar, A. (2006). Poverty and equity. Measurement, Policy and Estimation with DAD, New York et Ottawa, Springer-IDRC-CRDI.

Dyson, T., \& Moore, M. (1983). On kinship structure, female autonomy, and demographic 
behavior in India. Population and development review, 35-60.

Gourieroux, C., Monfort, A., \& Trognon, A. (1984). Pseudo maximum likelihood methods: Theory. Econometrica: Journal of the Econometric Society, 681-700.

Japan International Cooperation Agency (JICA). 2007. Cambodia: Country Gender Profile. Phnom Penh.

Jejeebhoy, S. J., \& Sathar, Z. A. (2001). Women's autonomy in India and Pakistan: the influence of religion and region. Population and development review, 27(4), 687-712.

Jöreskog, K.G. (1973). A general method for estimating a linear structural equation system. In Structural Equation Models in the Social Sciences, A.S. Goldberger and O.D Duncan (Eds.). New York: Seminar Press, pp. 85-112

Jöreskog, K. G., \& Goldberger, A. S. (1975). Estimation of a model with multiple indicators and multiple causes of a single latent variable. journal of the American Statistical Association, 70(351a), 631-639.

Kabeer, N. (1998). Money can't buy me love'. Re-evaluating gender, credit and empowerment in rural Bangladesh.

Kabeer (1999). Resources, Agency, Achievements: Reflections on the Measurement of Women's Empowerment. Development and Change Vol. 30, 435-464

Kabeer, N. (2012). Women's economic empowerment and inclusive growth: labour markets and enterprise development. International Development Research Centre.

Kishor, S. (2000, March). Women's contraceptive use in Egypt: What do direct measures of empowerment tell us?. In annual meeting of the Population Association of America, Los Angeles (pp. 23-25).

Klein, E. (2014). Psychological agency: Evidence from the urban fringe of Bamako. World Development, 64, 642-653.

Klein, E. \& Ballon, P. (2016) "Rethinking measures of psychological agency: A study of the urban fringe of Bamako" Paper presented at the 2015 HDCA General Conference, Washington, D.C.

Krishnakumar, J., \& Ballon, P. (2008). Estimating basic capabilities: A structural equation model applied to Bolivia. World Development, 36(6), 992-1010. 
Kuklys, W. (2005). Amartya Sen's capability approach: theoretical insights and empirical applications. Springer Science \& Business Media.

Laferrère, A., \& Wolff, F. C. (2006). Microeconomic models of family transfers. Handbook of the economics of giving, altruism and reciprocity, 2, 889-969.

Lindsey, L. L. (2015). Gender roles: A sociological perspective. Routledge.

Lundberg, S. \& Pollak, R. A. (1993). Separate spheres bargaining and the marriage market. Journal of Political Economy, 101, 988-1010

Malhotra, A., \& Schuler, S. R. (2005). Women's empowerment as a variable in international development. Measuring empowerment: Cross-disciplinary perspectives, 71-88.

Manser, M., \& Brown, M. (1980). Marriage and household decision-making: A bargaining analysis. International economic review, 31-44.

McElroy, M. B. (1990). The empirical content of Nash-bargained household behavior. Journal of human resources, 559-583.

McElroy, M. B., \& Horney, M. J. (1981). Nash-bargained household decisions: Toward a generalization of the theory of demand. International economic review, 333-349.

Muthén, B.O. (1984). A general structural equation model with dichotomous, ordered categorical, and continuous latent variable indicators. Psychometrika, 49(1), 115-132.

Muthén, B.O. (1998-2004). Mplus Technical Appendices. Los Angeles, CA: Muthén \& Muthén.

Narayan, D. (2005). Conceptual framework and methodological challenges. Measuring empowerment, 1.

Narayan, D., Pritchett, L., \& Kapoor, S. (2009). Moving Out of Poverty, Volume 2. Moving Out of Poverty, 2(1), 1-1.

Nussbaum, M. C. (2001). Women and human development: The capabilities approach (Vol. 3). Cambridge University Press.

Pitt, M. M., Khandker, S. R., \& Cartwright, J. (2006). Empowering women with micro finance: Evidence from Bangladesh. Economic Development and Cultural Change, 54(4), 791-831. 
Quisumbing, A. R. (2003). Household decisions, gender, and development: a synthesis of recent research. International Food Policy Research Institute.

Rowlands, J. (1995). Empowerment examined. Development in practice, 5(2), 101-107.

Sen, A. (1999). Commodities and capabilities. OUP Catalogue.

Skrondal, A., \& Rabe-Hesketh, S. (2004). Generalized latent variable modeling: Multilevel, longitudinal, and structural equation models. Crc Press.

Steiger, J. H., \& Lind, J. C. (1980, May). Statistically based tests for the number of common factors. In annual meeting of the Psychometric Society, Iowa City, IA (Vol. 758, pp. 424-453).

Sustainable Development Knowledge Platform, 2016, accessed 28/11/2016 https://sustainabledevelopment.un.org/sdg5

United States Agency for International Development (USAID) 2006 . Gender Analysis and Assessment . Volume I. Phnom Penh: USAID/Cambodia

White, H. (1982). Maximum likelihood estimation of misspecified models. Econometrica: Journal of the Econometric Society, 1-25. 